\title{
ANTI-ARTHRITIC POTENTIAL OF THE PLANT JUSTICIA GENDARUSSA BURM F
}

\author{
Jaijesh Paval, ${ }^{\mathrm{I}}$ Srinivasan Keloth Kaitheri, ${ }^{\mathrm{II}}$ Bhagath Kumar Potu, ${ }^{\mathrm{III}}$ Sreejith \\ Govindan, ${ }^{\text {IV }}$ Raju Suresh Kumar, ${ }^{\mathrm{V}}$ Sareesh Naduvil Narayanan, ${ }^{\mathrm{V}}$ Sudheer \\ Moorkoth $^{\text {II }}$
}

doi: $10.1590 / \mathrm{S1807-59322009000400015}$

Paval J, Kaitheri SK, Potu BK, Govindan S, Kumar RS, Narayanan SN, Moorkoth S. Anti-arthritic potential of the plant Justicia gendarussa Burm F. Clinics. 2009;64(4):357-62.

OBJECTIVE: To evaluate the anti-arthritic potential of the plant Justicia gendarussa using two different rat models.

MATERIALS AND METHOD: The anti-arthritic potential of the alcoholic extract of the plant Justicia gendarussa was evaluated using the Freund's adjuvant-induced and collagen-induced arthritic rat models. The rats were treated with the ethanolic extract of Justicia gendarussa and with standard aspirin.

RESULTS: The ethanolic extract of Justicia gendarussa showed significant anti-arthritic activity that was statistically similar to that of aspirin. Our results suggest that the alcoholic extract of Justicia gendarussa exhibits significant anti-arthritic potential.

KEYWORDS: Arthritis; Plant extract; Aspirin; Collagen; Rat.

\section{INTRODUCTION}

Rheumatoid arthritis (RA) is a ravaging inflammatory and autoimmune illness that affects the joints. ${ }^{1}$ This disease also affects the tissues surrounding the joints such as skin, blood vessels, and muscles. ${ }^{2}$ Although various drugs have been used to control RA, there are numerous reports regarding the side effects of these drugs. A range of newer drugs called TNF blockers have been linked to a condition called leukocytoclastic vasculitis, or LCV. ${ }^{3-5}$ TNF blockers, specifically Humira and Remicade, reportedly increase the risk of cancer and serious infections ${ }^{3}$. As a consequence, researchers are now searching for alternatives therapeutics. As part of this search, significant attention has been paid to the plant based drugs that are used in

IDepartment of Anatomy, Melaka Manipal Medical College - Manipal, Karnataka, India.

"Department of Pharmaceutical Chemistry, Manipal College of Pharmaceutical Science - Manipal, Karnataka, India.

II'Department of Anatomy, Kasturba Medical College - Manipal, Karnataka, India.

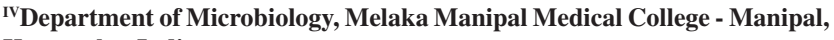
Karnataka, India.

v'Department of Physiology, Melaka Manipal Medical College - Manipal, Karnataka, India.

Email: jaijesh@yahoo.co.in

Tel.: 09880178255

Received for publication on September 18, 2008

Accepted for publication on December 19, 2008 traditional medicine because these drugs elicit few side effects and are inexpensive. ${ }^{5}$ One such plant that is widely used in Indian and Chinese traditional medicines but that has not been studied in a well-controlled experimental trial to date, is the species Justicia gendarussa (J. gendarussa).

Justicia gendarussa Burm F. (Family: Acanthaceae) is a shade-loving, quick-growing, evergreen plant mostly found in moist areas. It is believed to be native to China and is distributed widely across India, Sri Lanka, and Malaysia. In Indian and Chinese traditional medicine, the leaf of the plant is recommended to treat ailments such as fever, hemiplegia, rheumatism, arthritis, headache, earache, muscle pain, respiratory disorders, and digestive trouble. ${ }^{6,7}$ However, to our knowledge, there are no published scientific studies on the anti-arthritic activities of the leaves of J. gendarussa or its potential toxicity. Therefore, the objective of this study is to examine the anti-arthritic potential and toxicity of the ethanolic leaf extract of this plant.

\section{MATERIALS AND METHODS}

\section{Plant material}

J. gendarussa leaves were collected from Udupi (Karnataka district, India) in August, 2006. The plant was identified by the Department of Botany, Mahatma Gandhi 
Memorial College, Manipal, India, and the voucher specimen was kept in the institutional herbarium for future reference. Two kilograms of shade-dried leaves was blended to a fine powder and extracted with ethanol (95\%) using the soxhlet method. ${ }^{8}$ The extract was concentrated by distillation under reduced pressure and evaporated to dryness. The total yield of the dried powder was $65 \mathrm{~g}$.

\section{Experimental animals}

Male albino Wistar rats weighing approximately $180-200$ $\mathrm{g}$ were used for the studies. The animals were housed in cages under standard laboratory conditions (12/12 hour light/dark cycle at $25 \pm 5^{\circ} \mathrm{C}$ ). The rats were fed a commercial rat diet and water ad libitum and were divided into groups of six. All experiments were conducted following the ethical guidelines for the use of animals in research at our institution.

\section{Acute toxicity test}

A group of six rats was administered the plant extract in graded doses of $0.25,0.5,1.0,1.5$, and $2.0 \mathrm{~g} / \mathrm{kg}$ rat. Rats were continuously observed for mortality and behavioral responses for $48 \mathrm{hr}$ and once daily thereafter until the $14^{\text {th }}$ day. Dose selection was performed by taking $1 / 10^{\text {th }}$ of the lethal dose. Ld50 as obtained from this experiment was 1000 $\mathrm{mg} / \mathrm{kg}$ rat. The dose of the J. gendarussa extract selected for our experiment was therefore $100 \mathrm{mg} / \mathrm{kg}$ rat. Aspirin was used as a standard drug against which to compare the efficacy of $J$. gendarussa. The dose of aspirin was selected as $360 \mathrm{mg} / \mathrm{kg}$ rat by using a human-rat conversion factor.

\section{Induction of arthritis}

Arthritis was induced by injecting the rats with Freund's Complete Adjuvant (FCA DIVISION) or Bovine type II Collagen (COLLAGEN DIVISION). In the first method, $0.5 \mathrm{~mL}$ of FCA containing $10 \mathrm{mg}$ of dry heat-killed Mycobacterium butyricum $/ \mathrm{mL}$ in sterile paraffin oil (Difco Laboratories, Detroit, MI) was injected into the plantar surface of the left hind foot of the animal., ${ }^{9} 10$

In the second method, $0.1 \mathrm{~mL}$ of collagen emulsified with Incomplete Freund's adjuvant (IFA) was injected into the left hind foot. ${ }^{11}$ The degree of hind paw swelling in each animal was determined using a plethysmograph. A qualitative scoring system was used to assess the severity of paw inflammation. The absence of any visible swelling was given a score of 0 , mild redness and swelling of individual digits, regardless of the number of affected digits was given a score of 1 , moderate redness and swelling of the ankle was given a score of 2 , and severe redness and swelling of the entire paw including the digits was given a score of 3 . Rats with a score of 3 were considered arthritic and were used for subsequent experiments.

\section{Experimental design}

In each of the two divisions (FCA and COLLAGEN), animals were subdivided into four groups of 6 rats each, as illustrated in Figure 1: FCA Group I - Normal rats administered gum acacia (gum acacia was used as vehicle); FCA Group II - Arthritic rats administered gum acacia; FCA Group III - Arthritic rats administered Aspirin; FCA Group IV - Arthritic rats administered the leaf extract of J. gendarussa. COLLAGEN Group I - Normal rats administered gum acacia; COLLAGEN Group II - Arthritic rats administered gum acacia; COLLAGEN Group III - Arthritic rats administered Aspirin; COLLAGEN Group IV - Arthritic rats administered the leaf extract of J. gendarussa. J. gendarussa and Aspirin were administered starting on the $20^{\text {th }}$ day following the induction of arthritis and continued for 20 days. During the 20 days of treatment, the paw volumes of the animals were recorded at regular intervals. At the end of the $20^{\text {th }}$ day, animals were euthanized by cervical dislocation. Serum samples were collected for further biochemical assays.
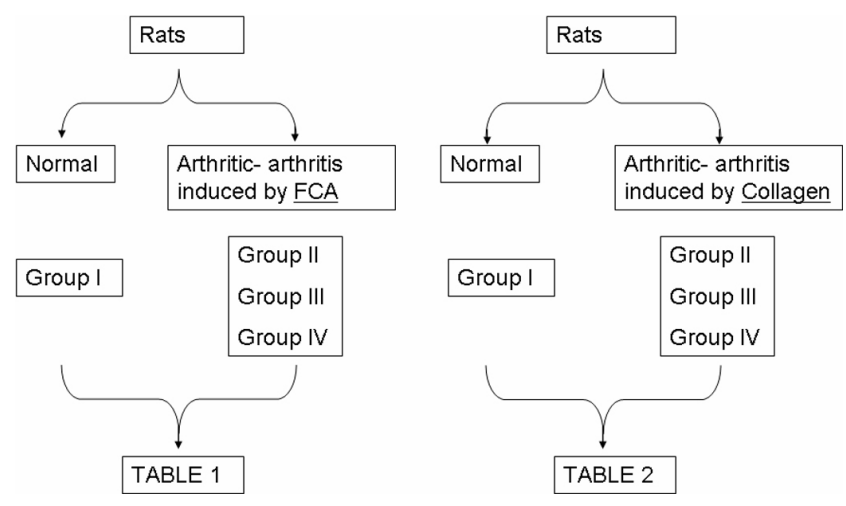

Figure 1 - Schematic representation of the experimental protocol

\section{Phytochemical screening}

The ethanolic extract of J. gendarussa was tested using standard procedures to identify the presence of sterols and flavonoids. Compounds separated using preparative paper chromatography were further assessed using the Liebermann-Burchard and Shinoda's tests to identify the presence of sterols and flavonoids, respectively.

\section{Biochemical assays}

Hemoglobin $(\mathrm{Hb})$ content was estimated by the method of Drabkin and Austin. ${ }^{12}$ Red blood cell (RBC) and white 
blood cell (WBC) counts were estimated according to the method of Chesbrough and McArthur ${ }^{13}$ in an improved Neubauer chamber. Estimations of erythrocyte sedimentation rates (ESR) were carried out by the method of Westergren. ${ }^{14}$ For the estimation of copper levels, the Colorimetric Bathocuproin disulfonate method of Zak and Landers ${ }^{15}$ was used. C-reactive protein levels were estimated using the ELISA kit obtained from Alpha Diagnostics Intl., USA.

\section{Statistical analysis}

The results were analyzed using one way Analysis Of Variance followed by the Bonferroni test. The values are expressed as means \pm SEM.

\section{RESULTS}

Acute toxicity tests showed an Ld50 of $1000 \mathrm{mg} / \mathrm{kg}$ with the leaf extract. We noted no behavioral or morphological changes when $1 / 10^{\text {th }}$ of the Ld50 was administered to a group of 6 rats for 40 days. Therefore, this dose was taken as the experimental treatment dose for the arthritic rats.

\section{Paw volume}

In arthritic rats, the paw volume reached its maximum on the $20^{\text {th }}$ day in both arthritic models. The paw maintained its inflamed condition for the next 20 days in Group II rats. A significant reduction in paw volume was observed in the J. gendarussa-treated (group IV) and aspirin-treated (group III) rats as compared to group II. The results are illustrated in Figures 2 and 3.

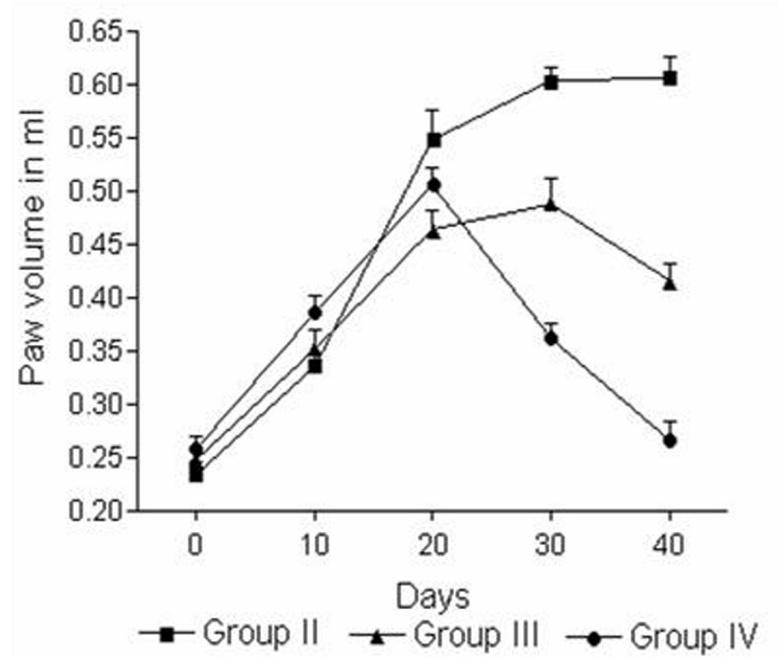

Figure 2 - Changes in the paw volumes of rats in group II (FCA-induced arthritic control), group III (FCA-induced arthritic rats treated with Aspirin), and group IV (FCA-induced arthritic rats treated with J. gendarussa extract). Values are mean $\pm \mathrm{SEM} ; \mathrm{n}=6 .{ }^{*} \mathrm{P}<.001$ for the comparison of groups III and IV with Group II on the $40^{\text {th }}$ day

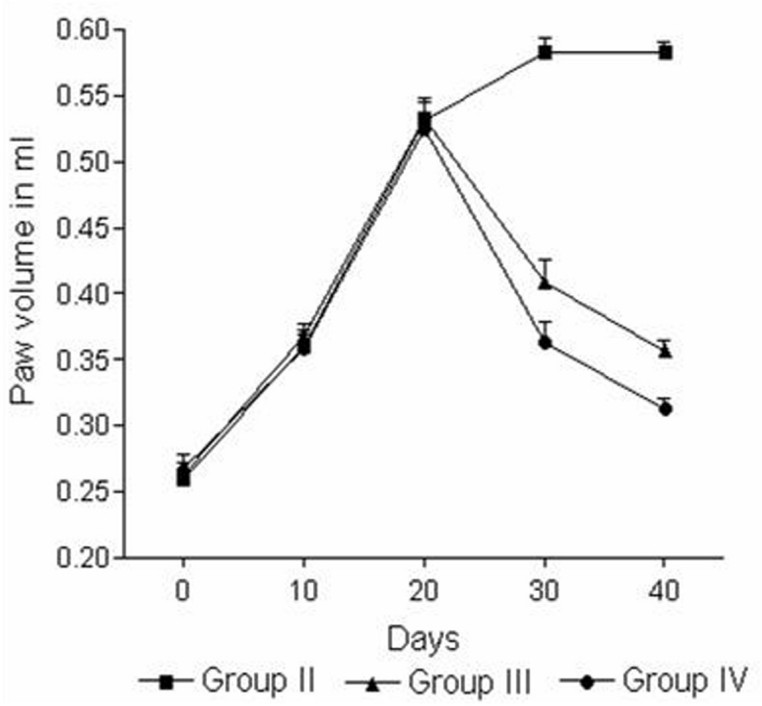

Figure 3 - Changes in the paw volumes of rats in group II (collagen-induced arthritic control), group III (collagen-induced arthritic rats treated with Aspirin), and group IV (collagen-induced arthritic rats treated with J. gendarussa extract). Values are mean $\pm \mathrm{SEM} ; \mathrm{n}=6 . * \mathrm{P}<.001$ for the comparison of groups III and IV with Group II on the $40^{\text {th }}$ day

\section{Hematological parameters}

Tables 1 (FCA) and 2 (COLLAGEN) show hematological parameters such as $\mathrm{Hb}, \mathrm{RBC}$ count, WBC count, ESR, serum copper levels, and C-reactive protein levels for both normal and experimental rats. We observed a similar trend in the hematological parameters from rats in the FCA and Collagen groups. A significant decrease in the levels of $\mathrm{RBC}$ and $\mathrm{Hb}$ was observed in arthritic rats (group II) when compared to normal rats (group I). Administration of J. gendarussa extract to arthritic rats (group IV) enhanced the levels of $\mathrm{Hb}$ and RBC to near normal levels. The increases in WBC count, ESR, serum C-reactive protein level, and serum copper level were significantly suppressed in the extract-administered arthritic group (group IV) (Table 2).

\section{DISCUSSION}

Freund's complete adjuvant (FCA)-induced arthritis and collagen-induced arthritis are two models that have been extensively used to study the pathogenesis of rheumatoid arthritis for therapeutics testing. ${ }^{10}$ Collagen-induced arthritis (CIA) is an experimental model that shares several clinical and pathological features with rheumatoid arthritis (RA). Scientists have established the importance of $\mathrm{T}$ cells in the pathogenesis of CIA and the role of cytokines in the progression of arthritis. ${ }^{16,17}$

Paw swelling is one of the major factors in assessing the degree of inflammation and curative efficacy of drugs. ${ }^{18}$ Here, the $J$. gendarussa-treated rats showed paw edema inhibition 
Table 1 - Effects of Aspirin (group III) and J. gendarussa extract (group IV) on hematological parameters in normal and FCA-induced arthritic rats. Values are mean \pm SEM; $n=6$

\begin{tabular}{lcccc}
\hline Parameter & Group I & Group II & Group III & Group IV \\
\hline $\mathrm{Hb}(\mathrm{g} / \mathrm{dL})$ & $12.25 \pm 0.21$ & $9.00 \pm 0.18^{\mathrm{a}}$ & $9.67 \pm 0.25$ & $11.75 \pm 0.21^{\mathrm{c}}$ \\
$\mathrm{RBC}\left(\mathrm{x} 10^{6} / \mathrm{mm}^{3}\right)$ & $4.48 \pm 0.01$ & $3.76 \pm 0.02^{\mathrm{a}}$ & $3.78 \pm 0.01$ & $4.14 \pm 0.17^{\mathrm{c}}$ \\
$\mathrm{WBC}\left(\mathrm{x} 10^{3} / \mathrm{mm}^{3}\right)$ & $7.34 \pm 0.14$ & $17.43 \pm 0.16^{\mathrm{a}}$ & $12.78 \pm 0.27^{\mathrm{b}}$ & $8.88 \pm 0.18^{\mathrm{c}}$ \\
ESR & $3.33 \pm 0.33$ & $10.67 \pm 0.42^{\mathrm{a}}$ & $10.50 \pm 0.43$ & $5.17 \pm 0.31^{\mathrm{c}}$ \\
CRP $(\mu \mathrm{g} / \mathrm{mL})$ & $172.9 \pm 3.47$ & $425.7 \pm 9.62^{\mathrm{a}}$ & $254.2 \pm 3.95^{\mathrm{b}}$ & $285.0 \pm 3.14^{\mathrm{c}}$ \\
Copper $(\mu \mathrm{g} / \mathrm{mL})$ & $103.2 \pm 7.27$ & $186.1 \pm 3.25^{\mathrm{a}}$ & $138.1 \pm 5.01^{\mathrm{b}}$ & $124.3 \pm 6.26^{\mathrm{c}}$ \\
\hline
\end{tabular}

${ }^{\mathrm{a}} \mathrm{P}<0.01$ for comparison of Group II and Group I; ${ }^{\mathrm{b}} \mathrm{P}<0.001$ for comparison of Group III and Group II; ${ }^{\mathrm{c}} \mathrm{P}<0.001$ for comparison of Group IV and Group II

Table 2 - Effect of Aspirin (group III) and J. gendarussa extract (group IV) on hematological parameters in normal and collagen-induced arthritic rats. Values are mean \pm SEM; $n=6$

\begin{tabular}{lcccc}
\hline Parameter & Group I & Group II & Group III & Group IV \\
\hline $\mathrm{Hb}(\mathrm{g} / \mathrm{dL})$ & $12.67 \pm 0.21$ & $8.92 \pm 0.15^{\mathrm{a}}$ & $9.17 \pm 0.28$ & $11.17 \pm 0.28^{\mathrm{c}}$ \\
$\mathrm{RBC}\left(\mathrm{x} 10^{6} / \mathrm{mm}^{3}\right)$ & $4.78 \pm 0.06$ & $3.52 \pm 0.09^{\mathrm{a}}$ & $3.41 \pm 0.15$ & $4.40 \pm 0.12^{\mathrm{c}}$ \\
$\mathrm{WBC}\left(\mathrm{x} 10^{3} / \mathrm{mm}^{3}\right)$ & $6.38 \pm 0.16$ & $4.23 \pm 0.25^{\mathrm{a}}$ & $8.24 \pm 0.22^{\mathrm{b}}$ & $7.48 \pm 0.13^{\mathrm{c}}$ \\
$\mathrm{ESR}$ & $4.17 \pm 0.31$ & $11.83 \pm 0.31^{\mathrm{a}}$ & $11.67 \pm 0.67$ & $5.83 \pm 0.40^{\mathrm{c}}$ \\
$\mathrm{CRP}(\mu \mathrm{g} / \mathrm{mL})$ & $76.87 \pm 2.43$ & $411.7 \pm 10.59^{\mathrm{a}}$ & $288.3 \pm 5.97^{\mathrm{b}}$ & $111.4 \pm 0.69^{\mathrm{c}}$ \\
Copper $(\mu \mathrm{g} / \mathrm{mL})$ & $118.5 \pm 7.27$ & $187.8 \pm 4.68^{\mathrm{a}}$ & $142.0 \pm 4.63^{\mathrm{b}}$ & $127.3 \pm 4.41^{\mathrm{c}}$ \\
\hline
\end{tabular}

${ }^{\mathrm{a}} \mathrm{P}<0.01$ for comparison of Group II and Group I; ${ }^{\mathrm{b}} \mathrm{P}<0.001$ for comparison of Group III and Group II; ${ }^{\mathrm{c}} \mathrm{P}<0.001$ for comparison of Group IV and Group II

of $43 \%$ in the FCA-induced arthritic model and $47 \%$ in the collagen-induced arthritic model. By comparison, aspirintreated rats showed paw edema inhibition rates of $26 \%$ and $38 \%$ in the FCA-induced arthritic model and the collageninduced arthritic model, respectively.

Anemia is commonly noted in patients with chronic arthritis. ${ }^{19}$ The two most common explanations are gastrointestinal blood loss due to arthritis medications and bone marrow changes in patients with inflammatory arthritis, which prevents the release of iron for incorporation into red blood cells. ${ }^{20,21}$ In our study, arthritic rats (group II) showed a reduced $\mathrm{RBC}$ count, reduced $\mathrm{Hb}$ levels, and an increased erythrocyte sedimentation rate (ESR). All these symptoms indicate an anemic condition, which persisted in the Aspirintreated group (group III). The J. gendarussa-treated group (group IV) showed a significant recovery from the induced anemia. The anemic condition persisted in the Aspirintreated group as indicated by the RBC count and $\mathrm{Hb}$ level. An indicator of infectious and inflammatory diseases, ${ }^{22}$ the WBC count was increased in arthritic rats. The migration of leukocytes to the inflamed area was significantly suppressed by this plant extract, as indicated by the significant decrease in the WBC count.

C-reactive protein is a member of the class of acute phase reactants - its levels rise dramatically during inflammatory processes. ${ }^{23}$ The concentration of C-reactive protein was found to be significantly reduced in the plant-treated as well as the Aspirin-treated groups.

Ceruloplasmin, an enzyme synthesized in the liver, contains 8 atoms of copper in its structure. Free copper ions are powerful catalysts of free radical damage. By binding copper, ceruloplasmin prevents free copper ions from catalyzing oxidative damage. ${ }^{24}$ Increased copper ion concentrations indicate the extent of an inflammatory condition. ${ }^{25}$ The concentration of serum copper was measured in both normal and arthritic rats. The arthritic rats exhibited significantly elevated copper levels, which were suppressed in J. gendarussa- and aspirin-treated rats.

Phytochemical analyses of the $J$. gendarussa leaf extract showed the presence of the flavonoids vitexin and apigenin. J. gendarussa extract has been reported to contain -sitosterols, alkaloids, reducing sugars, as well as unidentified sterols. ${ }^{26}$ Apigenin has been reported to exert anti-inflammatory effects such as lowering oxidative stress and forestalling the expression of several inflammatory factors. ${ }^{27}$ There are also reports on the flavonoid vitexin as a potent anti-inflammatory agent; vitexin may exert its anti-inflammatory activity by inhibiting the 5-lipoxygenase pathway, which together with the COX-2 pathway, is very important in producing and maintaining inflammation. ${ }^{28}$ 
Taken together, our results strongly support the antiarthritic potential of the plant $J$. gendarussa and its use in traditional medicine. As mentioned previously, compounds such as flavonoids and $\beta$-sitosterols are well known for their anti-inflammatory activities. The presence of these compounds in the $J$. gendarussa leaf extract may explain the anti-arthritic properties of this plant. Our next goal is to isolate and identify the compounds responsible for the antiarthritic potential of this plant.

\section{REFERENCES}

1. Billingham ME. Models of arthritis and the search for anti arthritic drugs. Pharmacol Ther. 1983;21(3):389-428.

2. Asolkar LV, Kakkar KK, Chakre OJ. Second Supplement to Glossary of Indian Medicinal Plants with Active Principles, Part I (A-K), (19651981). Publication and Information Directorate. New Delhi, 1992, xlvii, pp. 414.

3. Kavanaugh A, Cohen S, Cush JJ. The evolving use of tumor necrosis factor inhibitors in rheumatoid arthritis. J Rheumatol. 2004;31:10:18814.

4. Mohan N, Edwards ET, Cupps TR, Slifman N, Lee JH, Siegel JN, et al. Leukocytoclastic Vasculitis Blocking Agents; The Associated with TNF- Journal of Rheumatology. 2004;31:10:1955-8.

5. Dharamsiri MG, Jayakody JRAC, Galhena G, Liyanage SSP, Ratnasooriya WD. Anti inflammatory and analgesic activities of mature fresh leaves of Vitex negundo. J Ethnopharmacol. 2003; 87:199-206.

6. B.N. Sastri. Wealth of India: Raw materials, Vol. V,(Council of Scientific and Industrial Research, new Delhi, 1959) pp. 312-3.

7. D.M. Jayasinghe.Ayurveda Pharmacopeia, (Department Ayurveda, Colombo, Sri Lanka, 1979) pp. 30-2.

8. Somchit MN, Reezal I, Nur EI, Mutalib AR. In vitro antimicrobial activity of ethanol and water extracts of Cassia alata. J Ethnopharmacol. 2003;84:1-4.

9. Newbould BB. Chemotherapy of arthritis induced in rats by Mycobacterial adjuvant. Br J Pharmacol. 1963;21:127-36.

10. Mizushima Y, Tsukada W, Akimoto T. A modification of rat adjuvant arthritis for testing antirheumatic drugs. J Pharm Pharmacol. 1972;24:781-5.

11. Anthony DD, Haqqi TM. Collagen-induced arthritis in mice: an animal model to study the pathogenesis of rheumatoid arthritis. Clin Exp Rheumatol. 1999; 17:240-4.
12. Austin JH, Drabkin DL. Estimation of Haemoglobin. J. Biol. Chem $1935,112: 67$

13. Chesbrough M, Mc Arthur J. Laboratory Manual of Rural Tropical Hospitals. The English Language Book Society and Churchill Livingstone. 1972, p. 145.

14. David G, Sykes AJ. Westergren and Wintrobe methods of estimating ESR compared. Br Med J. 1951;2(4746):1496-7.

15. Landers JP. Handbook of Capillary Electrophoresis. CRC Press LLC, Danvers, USA. 2n Ed. 1996, p. 567-90.

16. Taneja V, Taneja N, Paisansinsup T, Behrens M, Griffiths M, Luthra H, et al. CD4 and CD8 T cells in susceptibility/protection to collagen-induced arthritis in HLA-DQ8-transgenic mice: implications for rheumatoid arthritis. J Immunol. 2002;168:5867-75.

17. Feldmann M, Brennan FM, Maini RN. Role of cytokines in rheumatoid arthritis. Annu Rev Immunol. 1996;14:397-440.

18. Begum VH, Sadique J. Long term effect of herbal drug Withania somnifera on adjuvant induced arthritis in rats. Indian J Exp Biol. $1988 ; 26: 877-82$.

19. Glen EM, Bowman BJ, Ronloff NA, Seely RJ. A major contributory cause of arthritis in adjuvant inoculated rats. Granulocytes. Agents Actions. 1977;7:265-82 .

20. Allar S, O'Driscoll J, Laurie A. Salmonella osteomyelitis in aplastic anaemia after anti-lymphocytic globulin and steroid treatment. J Clin Pathol. 1977; 2:174-5.

21. Mowat G. Haematological abnormalities in rheumatoid arthritis. Semin Arthritis Rheum. 1971;1:195-9.

22. Maria M, Engeniusz M, Miroslaw K, Maria K, Iwona P. Adjuvant induced disease in rats, clinical findings and morphological and biochemical changes in the blood histological changes in internal organs. Rheumatology. 1983;2:231-45. 
Paval J, et al.

23. McConkey B, Crockson RA, Crockson AP, Nilkinson AR. The effect of some anti inflammatory drugs on the acute-phase proteins in rheumatoid arthritis. Q J Med. 1973;32:785-91.

24. Revnic F: The Significance of Serum Ceruloplasmin in Diagnosis of Rheumatoid Arthritis. Toxicology Letters, Volume 78, Supplement 1, August 1995;70-70.

25. White AG, Scudder P, Dormandy TL, Martin VM. Copper-an index of erosive activity? Rheumatology.1978;17:3-5.
26. Wahi SP, Wahi AK, Kapoor R: Chemical study of the leaf of Justicia gendarussa Burm. JRIM. 1974;9:65-6.

27. Sawatzky D, Willoughby D, Colville-Nash P, Rossi A: The involvement of the apoptosis-modulating proteins Erk 1/2, Bcl-xL, and Bax in the resolution of acute inflammation in vivo. Am J Pathol. 2006;168:3341.

28. Sridhar C, Krishnaraju AV, Subbaraju GV. Antiinflammatory constituents of teramnus labialis. Indian Journal of Pharmaceutical Scineces. 2006;68:111-4. 